\title{
Efektivitas Penerapan Pendekatan Pembelajaran Realistic Mathematics Education (RME) terhadap Kemampuan Pemahaman Konsep
}

\author{
Fathu Ridha $^{1 *}$, Suharti ${ }^{2}$, Andi Halimah ${ }^{3}$, \& Fitriani Nur $^{4}$ \\ 1, 2,3,4 Universitas Islam Negeri Alauddin, Makassar, Indonesia
}

\begin{tabular}{l} 
INFO ARTICLES \\
\hline Article History: \\
Received: $30-12-2021$ \\
Revised: $25-04-2021$ \\
Approved: $22-06-2021$ \\
Publish Online: $30-06-2021$ \\
\hline
\end{tabular}

Key Words:

Realistic Mathematics Education; Concept Understanding;

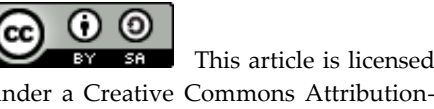
under a Creative Commons AttributionShareAlike 4.0 International License.

\begin{abstract}
This study intends to describe the effectiveness of the learning approach Realistic Mathematics Education (RME) towards increasing students' ability to understand mathematical concepts and and to determine the effectiveness of RME learning with conventional learning to increase students' ability to understand mathematical concepts. It is a Quasi Experiment research design is Nonequivalent Control Group Design. The population was class VII SMPN 3 Sungguminasa, the control class sample was class VII.E and the experimental class sample was class VII.F, with 32 students each. The data collection technique used a test in the form of essay questions. The data analysis technique was in the form of descriptive and inferential statistical analysis with t-test and effectiveness test. The results revealed that there were differences in students understanding of mathematical concepts with learning RME and without RME learning, and learning RME was more effective in improving students' conceptual understanding skills.
\end{abstract}

\begin{abstract}
Abstrak: Penelitian ini bermaksud untuk mendeskripsikan keefektifan pendekatan pembelajaran Realistics Mathematics Education (RME) terhadap peningkatan kemampuan pemahaman konsep matematika siswa dan untuk mengetahui keefektifan pembelajaran RME dengan pembelajaran konvensional terhadap peningkatan kemampuan pemahaman konsep matematika siswa. Merupakan penelitian Quasi Experiment yang desain penelitiannya Nonequivalent Control Group Design. Populasinya ialah kelas VII SMPN 3 Sungguminasa, sampel kelas kontrolnya ialah kelas VII.E dan sampel kelas eksperimennya ialah kelas VII.F yang jumlah siswanya masingmasing 32 orang. Adapun teknik pengumpulan data menggunakan tes berupa soal essay. Teknik analisis datanya berupa analisis statistik deskriptif dan inferensial dengan uji-t dan uji efektifitas. Hasilnya mengungkapkan ada perbedaan pemahaman konsep matematika siswa dengan pembelajaran RME dan bukan, serta pembelajaran RME lebih efektif dalam meningkatkan kemampuan pemahaman konsep siswa.
\end{abstract}

Correspondence Address: Jln. Samata, Gowa, Indonesia, e-mail: 20700115068@uin-alauddin.ac.id

How to Cite (APA $6^{\text {th }}$ Style): Ridha, F., dkk. (2021). Efektivitas Penerapan Pendekatan Pembelajaran Realistic Mathematics Education (RME) terhadap Kemampuan Pemahaman Konsep. JKPM (Jurnal Kajian Pendidikan Matematika), 6(2): 205-214.

Copyright: 2021 Fathu Ridha, Suharti Suharti, Andi Halimah, Fitriani Nur

Competing Interests Disclosures: The authors declare that they have no significant competing financial, professional or personal interests that might have influenced the performance or presentation of the work described in this manuscript. 


\section{PENDAHULUAN}

Aspek terpenting dalam kehidupan manusia ialah pendidikan. Proses yang dilalui dalam aspek ini mengantarkan manusia mendapat pengetahuan, nilai budaya, dan keterampilan sepanjang generasi (Fajarina, 2016). Dalam pendidikan, matematika seakan menjadi pelajaran wajib karena selalu diajarkan di tiap tingkatan (Megantara dkk., 2017). Poin yang menjadi alasan matematika dianggap penting karena aktivitas sehari-hari akan selalu berhubungan dengan matematika, seperti menjual atau membeli (Wicaksono, 2016). Target dari matematika ialah membentuk seorang pelajar berpikir logis untuk menguasai konsep, teliti, kritis, dan punya keterampilan dalam menyelesaikan masalah (Simalango, 2016). Keefektifnya pembelajaran hanya jika dalam sebuah kelas siswanya maksimal sebanyak 25 orang. Hal ini tentu mempengaruhi kualitas belajar mereka, terutama untuk pelajaran yang perlu pemahaman yang baik saat belajar seperti Matematika (Syafruddin \& Jeranah, 2020). Pemahaman materi akan membuat siswa tidak hanya sekedar menghafal. Apabila siswa sudah paham artinya mereka bisa menerima dengan baik dan tidak lagi memberi argument negatif pada suatu pelajaran (Nasir \& Sari, 2019).

Pemahaman konsep termasuk kemampuan yang perlu dikuasai oleh pelajar saat belajar matematika (Megantara et. al., 2017). Pemahaman konsep merupakan landasan pokok agar pelajar bisa memecahkan sebuah persoalan matematika (Kania \& Arifin, 2020). Dalam memahami (menguasai) suatu konsep, maka para siswa bukan cuma diasah dari segi keterampilan menghafal atau mengerjakan soal, tapi juga diasah berpikirnya "mengapa" sebuah soal dikerjakan seperti itu (Rismayanti \& Pujiastuti, 2020). Dengan memahami konsep suatu materi berarti pelajar tidak hanya bisa mengerjakan soal tapi juga mengaplikasikan materi itu di kehidupan nyata (Yulianty, 2019).

Berdasakan hasil survei di bulan November 2018 di SMP Negeri 3 Sungguminasa-Gowa, diperoleh bahwa kepiawaian siswa memahami konsep masih berkategori rendah. Ini dibuktikan dari hasil belajar ranah kongnitif, para siswa masih di bawah standar KKM. Terdapat sekitar 75\% siswa atau 96 orang dari 128 siswa yang hasil belajarnya belum mencapai KKM yaitu 75. Kurangnya pemahaman konsep matematika siswa tersebut diketahui saat siswa diberikan soal bentuk narasi, mereka belum biasa menulis hal yang diketahui dan ditanyakan soal, jadi siswa sering salah paham dengan yang dimaksud soal. Mereka juga belum menguasai konsep matematika karena mayoritas dari siswa masih sulit mengaplikasikan konsep saat memecahkan masalah. Para siswa hanya menghapal rumus namun tidak mampu mengaplikasikannya.

Inovasi yang bisa mengatasi masalah tersebut ialah dengan mengaplikasikan pendekatan pembelajaran Realistic Mathematics Education (RME). RME atau dikenal juga Pendekatan Matematika Realistik ialah pendekatan yang menginginkan siswa menghubungkan pengetahuan dan kepiawaian mereka dengan mengerjakan sebuah aktivitas di dalam proses belajarnya (Hidayat dkk, 2020). Jadi siswa punya gambaran tentang konsep sebuah materi karena permasalahannya akrab dengan kehidupan mereka sendiri (Ramadhanti \& Marlina, 2019). Di sini siswa berkolaborasi dengan temannya untuk menemukan sendiri konsep yang diajarkan (Fitriani dkk., 2010).

Orientasi lama pendidikan Indonesia cenderung menempatkan siswa sebagai obyek, guru sebagai pemegang kekuasaan paling tinggi, materinya bersifat subyek oriented, dan pengelolaannya bersifat terpusat, dan dalam paradigma yang baru orientasinya pendidikan lebih kepada proses pembelajaran dibanding mengajar (teaching to learning), pengelolaan strukturnya lebih fleksibel, para siswa dipandang mempunyai kemandirian, dan Pendidikan punya hubungan serta interaksi dengan kehidupan (Tandililing, 2010). Pemikiran ini mengidentikkan RME dengan keharusannya diberikan kesempatan to reinvent dengan arahan guru, dan reinvention konsep yang harus dari menjelajahi berbagai kondisi (Tandililing, 2010). Sintaks RME berkesinambungan dengan indikator kepiawaian generalisasi matematis yakni menyimpulkan 
sederet fakta, pengalaman, dan juga pengetahuan dari berbagai contoh kasus di kehidupan nyata yang benarbenar terjadi (Dani, dkk., 2017).

Sintaks yang sesuai prinsip dari pendekatan RME ialah dimulai dengan penguasaan kasus yang kontekstual (Shoimin, 2014) . Di sini pihak Pendidik membuat (soal) kontekstual dan siswa diberikan tugas memahami masalah yang diberikan. Pendidik meluruskan dengan memberi clue (petunjuk) seperlunya saja (terbatas) pada part tertentu yang dikuasai oleh siswa. Tahap ini karakter $R M E$ yang diterapkan yaitu karakteristik pertama. Lain dari itu, memberikan masalah kontekstual hal ini memberikan peluang dilaksanakannya prinsip pertama $R M E$. Selanjutnya menuntaskan terkait masalah kontekstual, siswa secara tersendiri ditugaskan memecahkan masalah kontekstual di buku siswa ataupun lembar kerja dengan cara mandiri (Jannah \& Towafi, 2020). Metode memecahkan jawaban masalah yang berbeda diutamakan. Pendidik memberikan motivasi dalam menuntaskan dengan memberikan arahan siswa dalam menemukan solusi dari soal. Contohnya: bagaimana kamu dapat mengetahui itu, bagaimana cara penyelesaiannya. Di tahap ini siswa didorong agar mendapatkan konsep dari soal matematika. Selain itu, pada tahap ini juga dituntun menggunakan serta membentuk model sendiri dan menggunakannnya agar mudah dalam menyelesaikan soal permasalahan. Pendidik tidak memberikan penyelesaian dari masalah tersebut, sebelum siswa mendapatkan penyelesaian secara mandiri. Langkah ini muncul tiap landasan dasar RME, sementara ciri-ciri RME yang timbul yaitu ciri-ciri ke-2, mengaplikasikan model. Selanjutnya, merundingkan jawaban dan membandingkan, siswa diharapkan merundingkan jawabannya dengan grup kecil masing-masing. Selanjutnya, hasil perundingan akan disesuaikan dengan perundingan kelas yang dipimpin pendidik. Tahapan ini bisa dipakai oleh siswa dalam membentuk keberaniannya mengemukakan opini, walaupun ada perbedaan dengan siswa lain ataupun pendidik. Ciri-ciri RME yang di tahap ini menggunakan ide siswa, untuk upaya mengaktifkan interaksi siswa satu dengan yang lainnya, antara pendidik dan siswa, serta antara sumber belajar dan siswa. Selanjutnya, menyimpulkan, dari kegiatan perundingan kelompok serta kelas tadi, pendidikan memberikan arahan siswa agar menarik kesimpulan mengenai konsep, teorema, definisi, prosedur atau prinsip matematika mengenai kasus kontekstual yang dikerjakan. Ciri-ciri RME yang akan timbul dalam sintaks ini yaitu penggunaan korelasi pendidik dan juga siswa.

Sebelumnya sudah ada yang meneliti dengan kasus serupa, seperti dari Hidayah dkk. yang mendapatkan hasil bahwa pendekatan RME bisa menumbuhkan kepiawaian pelajar dalam memahami konsep matematis, dan karena pencapaian itu pelajar yang mendapat pendekatan realistik lebih baik dari yang mendapat pendekatan kontekstual (Hidayat dkk., 2020). Lalu ada pemaparan bahwa pemahaman konsep bagi siswa yang mengikuti pembelajaran RME lebih tinggi dari yang mengikuti pembelajaran bukan RME (Megantara, 2017). Kemudian juga ada pencapaian final serta peningkatan kepiawaian generalisasi di kelas eksperimen lebih baik dari yang kelas kontrol (Dani, 2017). Model pembelajaran konvensional yang mudah diterapkan disekolah menjadi kontrol terhadap efek dari penerapan RME dalam penelitian ini.

Dilakukannya penelitian ini bermaksud untuk mendeskripsikan keefektifan pendekatan pembelajaran Realistic Mathematics Education (RME) pada kemajuan (peningkatan) kepiawaian pemahaman konsep matematika para siswa dan juga guna mengetahui keefektifan pembelajaran RME dengan pembelajaran konvensional dalam memajukan (meningkatkan) kemampuan pemahaman konsep matematika siswa.

\section{METODE}

Jenis penelitian yang diterapkan dalam penelitian ini ialah eksperimen semu. Rancangan penelitiannya ialah pretest-postest nonequivalent control grouup design. Dalam pelaksanaan rancangan penelitian ini diadakan 2 grup, grup pertama dinamakan eksperimen sementara grup kedua dinamakan kontrol. Kelas pertama menerapkan pendekatan pembelajaran Realistics Mathematics Education (RME) 
sementara kelas kedua menerapkan pembelajaran konvensional yang masing-masing kelas diberikan pretest dan postest. Sampel di penelitian ini merupakan para siswa dari kelas VIII E dan VIII F SMPN 3 Sungguminasa Kabupaten Gowa yang masing-masing siswanya berjumlah 32 orang. Penetian ini masuk dalam eksperimen semu desain pretest-posttest nonequivalen control group. Ada dua grup yakni grup (tim) eksperimen yang diaplikasikan pendekatan pembelajaran RME dan grup kontrol yang memakai pembelajaran konvensional. Data dikumpulkan dengan memberi pretest guna mengukur pemahaman konsep matematika siswa; memberlakukan pembelajaran RME di dalam kelas eksperimen, mengumpulkan informasi data setelah kelas eksperimen diberi perlakuan serta grup kelas kontrol yang diberikan posttest guna mengukur kemampuan pemahaman konsep matematika siswa.

Analisis (perhitungan) data dikerjakan secara statistik deskriptif untuk mengetahui mean, median, dan standar deviasi serta kategorisai pemahaman konsep sekaligus secara inferensial yang diawali dengan uji prasyarat berupa uji normalitas dan uji homogenitas yang dilanjutkan dengan uji t dan uji efektifitas. Perhitungan deskriptif bertujuan mendeskripsikan kondisi sebelum dan kondisi sesudah diberi perlakuan untuk dua kelas yang dilihat dari tiap variabel. Perhitungan inferensial berguna dalam memutuskan hasil berdasarkan perolehan data dan informasi selama kegiatan penelitian dilakukan.

\section{HASIL}

Hasil penelitian ini terdiri dari analisis deskriptif dari dua grup kelas yakni eksperimen dengan mengaplikasikan pendekatan RME, kemudian kelas kontrol dengan mengaplikasikan pendekatan konvensional. Kategori kepiawaian pemahaman konsep siswa di kelas grup eksperimen bisa dilihat dari Tabel 1.

Tabel 1. Kategori Kepiawaian Pemahaman Konsep Siswa (Grup Eksperimen)

\begin{tabular}{|c|c|c|c|c|c|}
\hline \multirow{2}{*}{$\begin{array}{c}\text { Tingkatan } \\
\text { Penguasaan }\end{array}$} & \multirow[t]{2}{*}{ Kategori } & \multicolumn{2}{|c|}{$\begin{array}{c}\text { Pretest } \\
\text { Kelas Eksperimen }\end{array}$} & \multicolumn{2}{|c|}{$\begin{array}{c}\text { Posttest } \\
\text { Kelas Eksperimen }\end{array}$} \\
\hline & & Frekuensi & Persentase $(\%)$ & Frekuensi & Persentase $(\%)$ \\
\hline $0-20$ & $\begin{array}{l}\text { Sangat } \\
\text { Rendah }\end{array}$ & 14 & 43.75 & 0 & 0 \\
\hline $21-40$ & Rendah & 16 & 50 & 0 & 0 \\
\hline $41-60$ & Sedang & 2 & 6.25 & 0 & 0 \\
\hline $61-80$ & Tinggi & 0 & 0 & 20 & 62.5 \\
\hline $81-100$ & $\begin{array}{l}\text { Sangat } \\
\text { Tinggi }\end{array}$ & 0 & 0 & 12 & 37.5 \\
\hline \multicolumn{2}{|c|}{ Total } & 32 & 100 & 32 & 100 \\
\hline
\end{tabular}

Sumber: diolah dari data penelitian

Dari informasi Tabel 1. bisa terlihat bahwa kepiawaian memahami konsep matematika siswa ketika pretest ada 14 siswa (43,75\%) masuk dalam kategori sangat rendah, 16 siswa (50\%) masuk dalam kategori tinggi, 2 siswa lainnya (6,25\%) masuk dalam kategori sedang. Sementara kepiawaian mereka memahami konsep saat posttest berubah, sudah tidak ada lagi $(0 \%)$ siswa yang masuk kategori rendah, sangat rendah, dan juga sedang, tapi 20 siswa (62,5\%) yang masuk kategori tinggi, sisanya masuk kategori sangat tinggi. 
Adapun kategori kepiawaian memahami konsep matematika di grup kontrol bisa dilihat di Tabel 2.

Tabel 2. Kategori Kepiawaian Pemahaman Konsep Matematika (Grup Kontrol)

\begin{tabular}{|c|c|c|c|c|c|}
\hline \multirow{2}{*}{$\begin{array}{c}\text { Tingkatan } \\
\text { Penguasaan }\end{array}$} & \multirow{2}{*}{ Kategori } & \multicolumn{2}{|c|}{ Pretest } & \multicolumn{2}{|c|}{ Posttest } \\
\hline & & Frekuensi & Persentase $(\%)$ & Frekuensi & Persentase $(\%)$ \\
\hline $0-20$ & $\begin{array}{l}\text { Sangat } \\
\text { Rendah }\end{array}$ & 15 & 46.875 & 0 & 0 \\
\hline $21-40$ & Rendah & 15 & 46.875 & 0 & 0 \\
\hline $41-60$ & Sedang & 2 & 6.25 & 0 & 0 \\
\hline $61-80$ & Tinggi & 0 & 0 & 21 & 65.625 \\
\hline $81-100$ & $\begin{array}{l}\text { Sangat } \\
\text { Tinggi }\end{array}$ & 0 & 0 & 11 & 34.375 \\
\hline \multicolumn{2}{|c|}{ Total } & 32 & 100 & 32 & 100 \\
\hline
\end{tabular}

Sumber: diolah dari data penelitian

Dari Tabel 2. terlihat kemampuan pemahaman konsep matematika siswa di grup kontrol saat sedang pretest ada masing-masing 15 siswa $(46,87 \%)$ berada dalam kategori rendah dan sangat rendah, dan 2 siswa $(6,25 \%)$ masuk kategori sedang. Sementara kepiawaian pemahaman konsep matematika mereka ketika sedang posttest berubah, ada 21 siswa $(65,67 \%)$ yang berkategori tinggi, sisanya masuk kategori sangat tinggi.

Sebelum data diuji hipotesis, terlebih dahulu data diuji prasyarat normalitas dan homogenitas, keseluruhan data berdistristibusi normal dan variana data berasal dari populasi yang homogen.

Tabel 3. Hasil Uji Independent Samples Test

\begin{tabular}{ccccc}
\hline Kelas & Rata-rata & $t_{\text {hitung }}$ & $t_{\text {tabel }}$ & Sig. \\
\hline $\begin{array}{c}\text { Posttest kelas Eksperimen } \\
\text { Posttest } \text { kelas Kontrol }\end{array}$ & 62 & 2.223 & 1.99 & 0.094 \\
\hline
\end{tabular}

Sumber: diolah dari data penelitian

Berdasarkan Tabel 3., posttest diidentifikasi rerata hasil belajarnya di kelas eksperimen ialah 62 dan kelas kontrol ialah 59,99. Dari Tabel 3. juga teridentifikasi $t_{\text {hitung }} 2,223>t_{\text {tabel }} 1,99$ yang signifikansinya $0,094<0,05$. Sehingga diperoleh kesimpulan bahwa terdapat perbedaan kemampuan pemahaman konsep pada kelas eksperimen dan kelas kontrol. Selanjutnya digunakan rumus efisiensi relatif untuk melihat keefektifan pembelajaran RME.

Telah diketahui dari perhitungan analisis deskriptif bahwa varians sampel kelas kontrol $\left(S_{1}^{2}\right)=$ 80,54 dan varians sampel kelas eksperimen $\left(S_{2}^{2}\right)=53,91$.

Sehingga diperoleh nilai $R$ :

$$
R\left(\hat{\theta}_{2}, \hat{\theta}_{1}\right)=\frac{\operatorname{Var} \hat{\theta}_{1}}{\operatorname{Var} \hat{\theta}_{2}}=\frac{80,54}{53,91}=1,49
$$

Berdasarkan nilai $R=1,49$ dapat dinyatakan sebagai $R>1(1,49>1)$, maka secara relatif $\hat{\theta}_{2}$ lebih efisien daripada $\hat{\theta}_{1}$. Artinya, penerapan pendekatan RME efektif terhadap peningkatan kemampuan pemahaman konsep matematika siswa kelas VII SMPN 3 Sungguminasa Kabupaten Gowa. 


\section{PEMBAHASAN}

Pemahaman konsep wajib diterapkan ketika belajar matematika agar pengetahuan yang diterima siswa tidak terbatas dalam materi yang ada di buku. Belajar matematika memang seharusnya lebih ditekankan pada pemahaman, karena ketika para siswa paham berarti mereka bisa mengerjakan soal meski telah diotak atik serta paham pengaplikasiannya dalam kehidupan (Chisara dkk., 2018). Pemahaman konsep akan sejalan dengan minat siswa belajar matematika. Indonesia sendiri masih masuk dalam kategori rendah dalam hal pemahaman konsep berdasarkan skor PISA yang diperoleh (Hidayat dkk., 2020). Penyebab lemahnya siswa ber-matematika diantaranya karena mereka tidak mengenali konsep dasar dari materi pokok pelajaran yang dibahas (Purwasih, 2015). Maka perlu ada usaha untuk meningkatkan pemahaman siswa terkait konsep materi.

Realistic Mathematics Education termasuk pendekatan pembelajaran yang sengaja dikembangkan guna mendekatkan para siswa dengan matematika (Hartono, 2017). Pendekatan ini mendorong siswa untuk berunding, mengeluarkan kemampuan mereka secara maksimal untuk menemukan sebuah jalan keluar dari aktivitas pembelajaran (Hidayat dkk., 2020). Hal ini sama dengan yang dipaparkan Purwasih bahwa pembelajaran bisa menjadi maksimal apabila pihak guru mendorong para siswa untuk aktif melakukan tanya jawab, kritis, menjelaskan, dan memberi alasan dari jawaban menggunakan bahasa sesuai dengan pemahaman mereka sendiri (Purwasih, 2015). Pendekatan RME ini memilih peristiwa fakta menjadi dasar utamanya. Kejadian di Dunia nyata yang benar-benar terjadi disampaikan kepada para siswa dalam bentuk aplikasi matematika. Cara ini lah yang dianggap dalam pendekatan RME yang bisa menolong siswa memahami konsep matematika (Hadi, 2018).

Beberapa kelebihan dari pendekatan RME yang dikemukakan Hobri ialah adanya definisi yang jelas sekaligus operasional saat pembelajaran berlangsung, pelaku (siswa) perlu menjalani sendiri kegiatan/aktivitas pembelajaran agar bisa menemukan sendiri suatu konsep berbantuan pihak yang sudah tahu (Bakoban, 2019). Kelebihan lain diungkapkan Wijaya yakni memberikan pengetahuan pada pelajar soal hubungan matematika dengan peristiwa sehari-hari yang mereka jalani; (2) memberi definisi kepada para siswa bahwasanya matematika itu bidang yang dikonstruksi dan juga dikembangkan oleh mereka sendiri, jadi bukan hanya para pakar dibidang itu (Wijaya, 2011).

Sementara kekurangan dari RME ialah: (1) siswa belum terbiasa menemukan jawaban dengan mandiri karena terbiasa diberikan dulu informasi; (2) butuh waktu belajar lama bagi yang sulit menangkap pelajaran; (3) siswa yang lebih pintar terkadang gelisah menunggu temannya yang belum selesai; (4) butuh alat peraga yang sesuai (Tandililing, 2010). Kelemahan ini juga dikemukakan Wijaya bahwa guru sulit mendorong para siswa menyelesaikan soal dengan berbagai cara, dan sulit juga bagi guru memberikan bantuan supaya mereka terus kembali melakukan penemuan suatu konsep (Wijaya, 2011). Kemudian ada pula komponen dari pendekatan RME, yakni: (1) Use of context (memakai konteks), (2) Use models, bridging by vertical instrument (memakai model), (3) Students contribution (memakai kontribusi dari siswa), (4) Interactivity (interaksi), dan (5) Intertwining (terintegrasi topik yang lain) (Chisara dkk., 2018).

Pendekatan pembelajaran RME mengkolaborasikan pandangan mengenai matematika itu apa, bagaimana belajar matematika, dan bagaimana cara mengajarkan matematika. RME menyampaikan sebuah materi berdasarkan hal-hal yang benar-benar terjadi di dalam kehidupan (Chisara dkk., 2018). Untuk bisa mengerti dan mengerjakan soal dengan baik meski bentuk soalnya divariasikan maka materi perlu dipahami, bukan dihafal.

Dari perhitungan pretest di kelas eksperimen, nilai rerata siswanya kebanyakan masuk dalam kategori rendah, yakni sebanyak 16 dari 32 orang atau 50\% dari jumlah siswa. Namun saat posttest hasilnya sangat berbeda, kebanyakan justru hasil test nya masuk kategori tinggi, yakni ada 20 dari 32 orang atau $62,5 \%$ dari jumlah siswa. Hasil ini membuktikan bahwasanya persentase kepiawaian memahami konsep 
matematika siswa di grup eksperimen ada pengembangan. Hasil ini sejalan dengan hasil yang di dapat Hidayah yang meneliti pembelajaran RME, dimana pemahaman konsep siswa skor rerata kelas eksperimen dalam penelitiannya masuk kategori rendah saat pretest, tapi pada saat posttest mengalami peningkatan (Hidayat, 2020). Untuk kelas kontrol persentase terbesar dalam mengukur pemahaman konsep siswa saat pretest masuk kategori rendah dan sangat rendah, namun saat posttest kategori pemahaman konsep siswa berubah menjadi kategori tinggi. Hasil ini pun sama dengan penelitian Bakoban bahwa pemahaman konsep kelas kontrol yang mengaplikasikan pembelajaran konvensional juga mengalami peningkatan (Bakoban, 2019).

Dari hasil uji statistik inferensial menggunakan uji independent samples test bisa disimpulkan ada perbedaan signifikan antara kelas yang diajar tanpa menggunakan pendekatan pembelajaran Realistic Mathematics Education (RME) dan kelas yang diajar menggunakan pendekatan pembelajaran Realistic Mathematics Education (RME) terhadap kemampuan pemahaman konsep matematika siswa kelas VII SMPN 3 Sungguminasa Kabupaten Gowa. Dari pengkajian dan hasil análisis oleh peneliti menyatakan pembelajaran dengan pendekatan pembelajaran Realistic Mathematics Education (RME) bisa dipakai untuk model pembelajaran dalam matematika yang berhubungan dalam kehidupan sehari-hari. Hal tersebut didasarkan pada pembelajaran matematika menggunakan pendekatan Realistic Mathematics Education (RME) bisa meningkatkan komunikasi serta interaksi sesama siswa dengan hal tersebut ia merasa malu bertanya kepada guru, pembelajaran matematika menggunakan pendekatan Realistic Mathematics Education (RME) menyebabkan siswa tidak cepat bosan karena siswa saling berdiskusi bersama kelompoknya. Pendekatan RME dianggap lebih efektif dibandingkan pendekatan konvensional dalam hal untuk meningkatkan pemahaman konsep para siswa karena pendekatan RME memanfaatkan realita dalam menyampaikan materi (Purnama dkk., 2018).

Hal ini juga disebabkan oleh pembelajaran dalam matematika yang memakai pendekatan Realistic Mathematics Education (RME) yang akan membentuk tanggung jawab setiap siswa mengenai tanggung jawabnya dalam kelompok untuk memahami dan menyelesaikan tugas yang ada, pembelajaran matematika yang menggunakan Realistic Mathematics Education (RME) yang akan membentuk keberanian siswa dalam menyampaikan hasil diskusi kelompok yang dipaparkan dihadapan teman sekelasnya, dan pembelajaran matematika yang menggunakan Realistic Mathematics Education (RME) akan membentuk siswa aktif serta memberikan peluang siswa untuk mengungkapkan ide matematis dengan memaparkan informasi disertai argument dalam diskusi kelompok ataupun antar kelompok, peran guru sebagai fasilitator dalam pembelajaran, dan melatih siswa menghargai pendapat orang lain (Chisara dkk., 2018).

Berdasarkan uji efektivitas, maka diperoleh bahwa pembelajaran Realistic Mathematics Education lebih efektif terhadap kemampuan pemahaman konsep matematika siswa kelas VII SMPN 3 Sungguminasa dibandingkan dengan pembelajaran tanpa menerapkan pendekatan pembelajaran Realistic Mathematics Education terhadap siswa kelas VII SMPN 3 Sungguminasa. Hasil ini juga sama dengan yang diperoleh Bakoban dalam penelitiannya bahwa pendekatan RME cukup lebih efektif jika dibandingkan pembelajaran biasa dalam hal meningkatkan pemahaman konsep siswa (Bakoban, 2019). Dari hasil penelitian Nur'aini menyatakan pendekatan pembelajaran RME akan menumbuhkan pemahaman, aktivitas serta sikap positif anak pada pelajaran matematika (Nur'aini dkk., 2016). Penelitian lain yang dilakukan oleh Rahayu juga menunjukkan adanya pengaruh positif pendekatan pembelajaran RME pada pemahaman konsep matematika siswa (Rahayu, 2016).

Adapun faktor penyebab kelas Realistic Mathematics Education lebih baik dari konvensional, yaitu siswa lebih aktif dalam pembelajaran karena metode ini dirasakan sebagai hal yang baru oleh siswa dan berbeda dengan pembelajaran konvensional, serta sebagian siswa lebih aktif saat pembelajaran berlangsung menggunakan metode tersebut, walaupun tidak semua ikut aktif jika dibandingkan kelas konvensional. Realistic Mathematics Education menolong siswa untuk menemukan sendiri konsepnya (Bakoban, 2019). 
Kegiatan ini artinya guru benar-benar hanya bertindak sebagai fasilitator, moderator, dan juga evaluator (Chisara dkk., 2018). Tidak hanya itu, beberapa aspek yang juga difasilitasi oleh pembelajaran RME diantaranya: (1) matematika jadi tidak begitu formal, abstrak, dan lebih menarik; (2) meninjau tingkatan kemampuan para siswa; (3) menitikberatkan belajar ke learning by doing; (4) terfasilitasi pengerjaan kasus tanpa memakai algoritma yang baku; dan (5) memakai konteks di permulaan kegiatan pembelajaran (Tandililing, 2010).

\section{SIMPULAN}

Pendekatan Pembelajaran RME efektif untuk peningkatan kepiawaian siswa memahami konsep matematika. Tidak hanya itu, ada juga perbedaan keefektifan pembelajaran antara grup eksperimen dan grup kontrol yang mengaplikasikan 2 pendekatan yang berbeda hal ini diperkuat dari nilai rata-rata posttest yang berbeda, sehingga membuktikan pendekatan RME lebih ampuh meningkatkan kepiawaian memahami konsep dari pembelajaran konvensional diliat dari uji efektifitas.

\section{DAFTAR RUJUKAN}

Bakoban, F. I. (2019). Pengaruh Pendekatan RME Terhadap Pemahaman Konsep Matematika Siswa Kelas VII di SMP Negeri 13 Medan. Prosiding SiManTap: Seminar Nasional Matematika Dan Terapan, 3439. https://bulletin.indoms-acehsumut.org/index.php/simantap/article/view/32

Chisara, C., Hakim, D. L., \& Kartika, H. (2018). Implementasi Pendekatan Realistic Mathematics Education (RME) dalam Pembelajaran Matematika. Presiding Sesiomadika, 65-72. https://journal.unsika.ac.id/index.php/sesiomadika/article/view/2097

Dani, S., Pujiastuti, H., \& Sudiana, R. (2017). Pendekatan Realistic Mathematics Education untuk Meningkatkan Kemampuan Generalisasi Matematis Siswa. Jurnal Penelitian Dan Pembelajaran Matematika, 10(2), 182-193. https://doi.org/http://dx.doi.org/10.30870/jppm.v10i2.2043

Fajarina, A. R. (2016). Hubungan antara Penggunaan Media Gambar dengan Prestasi Belajar IPS Siswa [Universitas Lampung]. hrrp://jurnal.fkip.unila.ac.id/index.php/pedagogi/article/viewFile/11141/7940

Fitriani, M., Hartono, Y., \& Purwoko. (2010). PENGEMBANGAN PERANGKAT PEMBELAJARAN MATEMATIKA DENGAN PENDEKATAN KUANTUM DI KELAS VIII SMP 2010. Jurnal Pendidikan Matematika, 4(1). https://doi.org/http://doi.org/10.22342/jpm.4.1.311.

Hadi, S. (2018). Pendidikan Matematika Realistik Teori, Perkembangan, dan Implementasinya. Jakarta: Rajawali Grafindo Persada.

Hartono, Y. (2017). Pengembangan Pembelajaran Matematika SD. Jakarta: Dirjen Dikti Depdiknas.

Hidayat, E. I. F., Yandhari, I. A. V., \& Alamsyah, T. P. (2020). Efektivitas Pendekatan Realistic Mathematics Education (RME) untuk Meningkatkan Kemampuan Pemahaman Konsep Matematika Siswa Kelas V. Jurnal Ilmiah Sekolah Dasar, 4(1), 106-113. https://doi.org/http://dx.doi.org/10.23887/jisd.v4i1.21103

Jannah, U.R., \& Towafi. 2020. Realistic Mathematic Education pada Barisan dan Deret Aritmatika Berbasis Kehidupan Islami Pondok Pesantren. Jurnal Kajian Pendidikan Matematika, 5(2), 165-174. https://journal.lppmunindra.ac.id/index.php/jkpm/article/view/5163/pdf

Kania, N., \& Arifin, Z. (2020). Aplikasi Macromedia flash untuk Meningkatkan Pemahaman Konsep Matematika Siswa. JNPM (Jurnal Nasional Pendidikan Matematika), 4(1), 96-109.

Megantara, M. I., Asnawati, R., \& Gunawibowo, P. (2017). Efektivitas Pendekatan Realistic Mathematics Education Ditinjau dari Pemahaman Konsep Matematis Siswa. Jurnal Pendidikan Matematika Unila, 
5(7), 830-841. http://jurnal.fkip.unila.ac.id/index.php/MTK/article/view/13827

Nasir, A. M., \& Sari, I. E. (2019). Efektivitas Model Realistic Mathematics Education (RME) dengan Menggunakan Alat Peraga Terhadap Prestasi Belajar. Jurnal Pedagogik, 6(1), 145-171. https://doi.org/https://doi.org/10.33650/pjp.v6i1.557

Nur'aini, E. S., Irawati, R., \& Julia. (2016). Pengaruh Pendekatan Realistic Mathematics Education (RME) terhadap Kemampuan Pemahaman Matematis dan Kepercayaan Diri Siswa pada Materi Menyederhanakan Pecahan. Jurnal Pena Ilmiah, 1(1), 691-700. https://ejournal.upi.edu/index.php/penailmiah/article/download/3559/pdf

Purnama, A., Suryana, Y., \& Elan. (2018). Peningkatan Pemahaman Konsep Bangun Datar Segitiga Melalui Pendekatan Realistic Mathematics Education di Kelas II SD. Indonesian Journal of Primary Education, 2(1), 78-86. https://doi.org/https://doi.org/10.17509/ijpe.v2i1.13751

Purwasih, R. (2015). Peningkatan Kemampuan Pemahaman Matematis dan Self Confidence Siswa MTs di Kota Cimahi melalui Model Pembelajaran Inkuiri Terbimbing. Jurnal Ilmiah STKIP Siliwangi Bandung, 9(1), 16-25. http://e-journal.stkipsiliwangi.ac.id/index.php/didaktik/article/view/113

Rahayu, S. (2016). Pengaruh Pendekatan Realistic Mathematics Education terhadap Pemahaman Konsep Matematika Siswa Kelas VII Madrasah Tsanawiyah Hasanah Pekan Baru [UIN Suska Riau]. http://repository.uin-suska.ac.id/id/eprint/2195

Ramadhanti, E., \& Marlina, R. (2019). Pembelajaran Realisric Mathematic Education (RME) terhadap Kemampuan Pemahaman Matematis. Prosiding Seminar Nasional Matematika Dan Pendidikan Matematika, 876-882. https://journal.unsika.ac.id/index.php/sesiomadika/article/view/2539/1937

Rismayanti, T.A., \& Pujiastuti, H..2020. Pengaruh Model Search Solve Create Share (SSCS) Terhadap Kemampuan Pemahaman Konsep Matematis. Jurnal Kajian Pendidikan Matematika, 5(2), 183-190. https://journal.lppmunindra.ac.id/index.php/jkpm/article/view/6345

Shoimin, A. (2014). Model Pembelajaran Inovatif dalam Kurikulum 2013. Yogyakarta: Ar-Ruzz Media.

Simalango, E. N. D. S. (2016). Efektivitas Pendekatan Realistic Mathematics Education (RME) Terhadap Kemampuan Pemecahan Masalah dan Pemahaman Konsep di Kelas VII SMP Negeri 17 Medan T.A 2015/2016 [Universitas HKBP Nommensen]. http://repository.uhn.ac.id/handle/123456789/337

Syafruddin, F., \& Jeranah. (2020). Efektivitas Penerapan Model Quantum Learning dengan Pendekatan Realistic Mathematics Education (RME) Terhadap Hasil Belajar Siswa. Al-Asma: Journal of Islamic Education, 2(2), 224-235. http://103.55.216.56/index.php/alasma/article/view/17487

Tandililing, E. (2010). Implementasi Realistic Mathematics Education (RME) di Sekolah. Jurnal Guru Membangun, 25(3), 1-9. https://jurnal.untan.ac.id/index.php/jgmm/article/view/208

Wicaksono, S. (2016). The Development Of Interactive Multimedia Based Learning Using Macromedia Flas 8 in Accouting Course. Journal Of Accounting Buisniess Education, 1(1), 122-139. http://dx.doi.org/10.26675/jabe.v1i1.6734

Wijaya, A. (2011). Pendidikan Matematika Realistik Suatu Alternatif Pendekatan Pembelajaran Matematika. Yogyakarta: Graha Ilmu.

Yulianty, N. (2019). Kemampuan Pemahaman Konsep Matematika Siswa dengan Pendekatan Pembelajaran Matematika Realistik. Jurnal Pendidikan Matematika Raflesia, 4(1), 60-65. https://doi.org/https://doi.org/10.33449/jpmr.v4i1.7530 
214 Ridha, dkk

JKPM (Jurnal Kajian Pendidikan Matematika) Vol.6, No.2 (2021) 